\title{
LISTAGEM, DISTRIBUIÇÃO GEOGRÁFICA E CONSERVAÇÃO DAS ESPÉCIES DE Cactaceae no estado do Rio de Janeiro
}

\author{
Alice de Moraes Calvente ${ }^{1}$, Maria de Fátima Freitas ${ }^{2}$ \\ \& Regina Helena Potsch Andreata ${ }^{3}$
}

\section{ReSUMO}

(Listagem, distribuição geográfica e conservação das espécies de Cactaceae no estado do Rio de Janeiro ) Este trabalho apresenta a listagem, distribuição geográfica estado de conservação das espécies de Cactaceae no estado do Rio de Janeiro. Foram utilizadas como referência as coleções dos principais herbários do estado e a literatura especializada. Os resultados apontam a ocorrência de 45 espécies subordinadas a 13 gêneros. Dez espécies foram listadas dentro de categorias de ameaça e sete são endêmicas para o estado. A maior riqueza para a família foi encontrada no mu nicípio do Rio de Janeiro que, apesar da alta pressão antrópica, apresenta 30 espécies. Destaca-se, no levantamento, o gênero Rhipsalis, como o mais representativo, com 23 espécies. Palavras-chave: floresta atlântica, lista de espécies, conservação, Rio de Janeiro.

\begin{abstract}
(Checklist, geografic distribution and conservation of the Cactaceae species of Rio de Janeiro State, Brazil) This work presents the Cactaceae checklist with geographical distribution and conservation status for the Rio de Janeiro State. The collections of the main herbaria in the State and the related bibliography were used as source of data. The results indicate the occurrence of 45 species distributed in 13 genera. Ten species are listed under threat categories and seven are State endemics. Despite the elevated urbanization pressure Rio de Janeiro was found as the most diverse municipality with 30 species. The genus Rhipsalis is notable in this checklist presenting 23 species.
\end{abstract}

Key-words: Atlantic forest, checklist, conservation, Rio de Janeiro.

\section{INTRODUÇÃo}

A família Cactaceae compreende 113 gêneros e 1.306 espécies (Hunt 1999) com distribuição somente nas Américas, com exceção de Rhipsalis baccifera (J. S. Mueller) Stearn que ocorre na região neotropical e, a leste, até o Sri Lanka (Taylor 1997). Em Cactaceae, o caule apresenta-se modificado em cladódios aplanados ou cilíndricos dotados de botões meristemáticos denominados aréolas, de onde emergem os tricomas, cerdas, flores, frutos e novos ramos (Freitas 1990/1992).

O estado do Rio de Janeiro possui, em sua cobertura vegetal a floresta pluvial atlântica e seus ecossistemas associados, como a restinga e o mangue. Sua área florestal remanescente está atualmente reduzida a aproximadamente 17\% da original (Rocha et al. 2003).
Na floresta pluvial atlântica a família Cactaceae se destaca pelo predomínio da riqueza de espécies em detrimento à abundância das mesmas. Nesse hábitat ocorrem principalmente as formas epífitas ou rupícolas. Já na restinga predomina a abundância de espécies, sendo que essas são, preferencialmente terrestres.

A diversidade e a conservação da mata atlântica têm especial relevância por ser esse um bioma prioritário em termos de conservação em nível global, com elevada biodiversidade e endemismo (Mittermeier et al. 2000). Dentro deste contexto está o estado do Rio de Janeiro, considerado um dos maiores centros de endemismo do Brasil e que se destaca como uma importante região a ser preservada em razão de sua enorme riqueza para diversos

\footnotetext{
Artigo recebido em 02/2004. Aceito para publicação em 03/2005.

${ }^{1}$ Museu Nacional/ UFRJ. Pós-Graduação em Botânica, Museu Nacional, Quinta da Boa Vista, São Cristóvão, Rio de Janeiro, RJ. CEP:20940-040. Bolsista da CAPES. alicecalvente@yahoo.com.

${ }^{2}$ Instituto de Pesquisas Jardim Botânico do Rio de Janeiro, Programa Zona Costeira. Rua Pacheco Leão 915, Rio de Janeiro, RJ. CEP: 22460-030. ffreitas@ jbrj.gov.br.

${ }_{3}^{3}$ Universidade Santa Úrsula, Laboratório de Angiospermas, ICBA. Rua Fernando Ferrari, 76, Botafogo- Rio de Janeiro. Bolsista do CNPq.randreat@bol.com.br.
} 
grupos da flora e fauna. A pressão exercida por grandes centros urbanos próximos aos remanescentes de mata atlântica no estado promove a formação de um número crescente de fragmentos, causando a insularização das populações de animais e vegetais (Rocha $e t$ al. 2003).

Neste cenário de ameaça, cabe aos pesquisadores criar subsídios sólidos, que contribuam para que se priorize a conservação da diversidade vegetal. Inicialmenteé necessário que se levantem dados científicos, como valores qualitativos e quantitativos de diversidade biológica, para que se conheça o que e o quanto devem ser preservados. A partir daí é importante que se procure difundir estes dados junto à comunidade científica, para que se possa unilos com outros já disponíveis e, conjuntamente, valorar estes recursos frente à sociedade. É necessário compreender que trabalhar pela conservação e desacelerar a perda de espécies e de comunidades biológicas é de interesse próprio da sociedade em todos os seus segmentos (Primack \& Rodrigues 2001).

Este trabalho fornece uma listagem das espécies de Cactaceae que ocorrem na vegetação natural do estado do Rio de Janeiro, apresentando dados atualizados sobre o seu grau de preservação, os ecossistemas que habitam e sua distribuição geográfica.

\section{Material e Métodos}

Foram consideradas neste trabalho apenas as espécies listadas em Hunt (1999), excluindo-se os táxons infra-específicos.

O levantamento foi realizado com base na literatura especializada e no exame dos espécimes depositados até 2002 nos principais herbários do Estado do Rio de Janeiro: FCAB, GUA, HB, R, RB, RBR, RFA, RUSU (siglas segundo Holmgren et al. 1990).

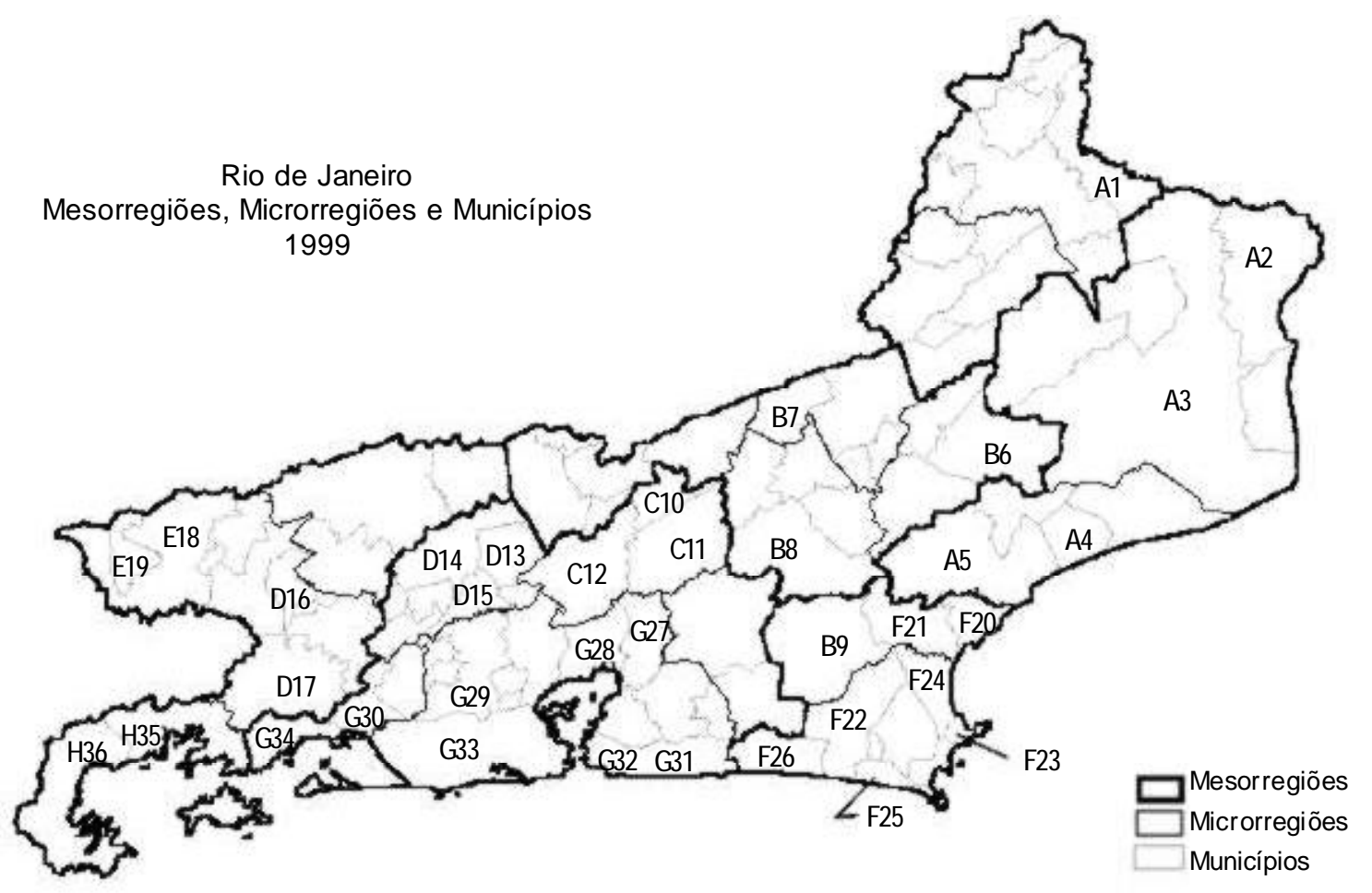

Figura 1 - Estado do Rio de Janeiro e sua divisão em municípios, meso e microrregiões. Os municípios onde ocorrem espécies da família Cactaceae estão definidos nos códigos da Tabela 1. Fonte: modificado do IBGE 1999 (www.ibge.org.br). 
Tabela 1 - Lista dos municípios do estado do Rio de Janeiro onde foram registradas ocorrências das espécies de Cactaceae, agrupados por meso e/ou microrregiões (adaptado de IBGE 1999) e situados em blocos de vegetação (adaptado de Rocha et al., 2003). Os municípios que apresentam maior riqueza de espécies estão destacados em negrito.

\begin{tabular}{|c|c|c|c|c|}
\hline Bloco & Região & Município & Código de referência & No de espécies \\
\hline Norte Fluminense & A & $\begin{array}{l}\text { Bom Jesus de Itabapoana } \\
\text { São João da Barra } \\
\text { Campos } \\
\text { Quissamã } \\
\text { Macaé }\end{array}$ & $\begin{array}{l}\text { A1 } \\
\text { A2 } \\
\text { A3 } \\
\text { A4 } \\
\text { A5 }\end{array}$ & $\begin{array}{c}1 \\
7 \\
4 \\
1 \\
\mathbf{1 8}\end{array}$ \\
\hline Serrano Central & B & $\begin{array}{l}\text { Santa Maria Madalena } \\
\text { Carmo } \\
\text { Nova Friburgo } \\
\text { Silva Jardim } \\
\text { São José do Rio Preto } \\
\text { Teresópolis } \\
\text { Petrópolis }\end{array}$ & $\begin{array}{l}\text { B6 } \\
\text { B7 } \\
\text { B8 } \\
\text { B9 } \\
\text { C10 } \\
\text { C11 } \\
\text { C12 }\end{array}$ & $\begin{array}{c}3 \\
3 \\
12 \\
1 \\
1 \\
2 \\
16 \\
13\end{array}$ \\
\hline Central Sul & $\mathrm{D}$ & $\begin{array}{l}\text { Paty do Alferes } \\
\text { Vassouras } \\
\text { Miguel Pereira } \\
\text { Volta Redonda } \\
\text { Rio Claro }\end{array}$ & $\begin{array}{l}\text { D13 } \\
\text { D14 } \\
\text { D15 } \\
\text { D16 } \\
\text { D17 }\end{array}$ & $\begin{array}{l}1 \\
1 \\
2 \\
1 \\
1\end{array}$ \\
\hline Serra da Mantiqueira & $\mathrm{E}$ & $\begin{array}{l}\text { Resende } \\
\text { Itatiaia }\end{array}$ & $\begin{array}{l}\text { E18 } \\
\text { E19 }\end{array}$ & $\begin{array}{l}3 \\
8\end{array}$ \\
\hline Região dos Lagos & $\mathrm{F}$ & $\begin{array}{l}\text { Rio das Ostras } \\
\text { Casimiro de Abreu } \\
\text { Araruama } \\
\text { Búzios } \\
\text { Cabo Frio } \\
\text { Arraial do Cabo } \\
\text { Saquarema }\end{array}$ & $\begin{array}{l}\text { F20 } \\
\text { F21 } \\
\text { F22 } \\
\text { F23 } \\
\text { F24 } \\
\text { F25 } \\
\text { F26 }\end{array}$ & $\begin{array}{c}1 \\
3 \\
2 \\
2 \\
8 \\
6 \\
\mathbf{1 1}\end{array}$ \\
\hline Metropolitano & G & $\begin{array}{l}\text { Guapimirim } \\
\text { Magé } \\
\text { Nova Iguaçu } \\
\text { Itaguaí } \\
\text { Maricá } \\
\text { Niterói } \\
\text { Rio de Janeiro } \\
\text { Mangaratiba }\end{array}$ & $\begin{array}{l}\text { G27 } \\
\text { G28 } \\
\text { G29 } \\
\text { G30 } \\
\text { G31 } \\
\text { G32 } \\
\text { G33 } \\
\text { G34 }\end{array}$ & $\begin{array}{c}1 \\
6 \\
5 \\
1 \\
9 \\
\mathbf{1 4} \\
\mathbf{2 9} \\
9\end{array}$ \\
\hline Sul Fluminense & $\mathrm{H}$ & $\begin{array}{l}\text { Angra dos Reis } \\
\text { Parati }\end{array}$ & $\begin{array}{l}\text { H35 } \\
\text { H36 }\end{array}$ & $\begin{array}{l}14 \\
12\end{array}$ \\
\hline
\end{tabular}

A distribuição geográfica das espécies noestado foi estabelecida através dos dados obtidos no levantamento. Os municípios em que as espécies ocorrem estão agrupados em oito regiões adaptadas das meso e microregiões geográficas definidas pelo IBGE em 1999 (www.ibge.gov.br) e, cada uma, possui um código de referência (Fig. 1/Tabela 1). Essas regiões primariamente definidas foram agrupadas e/ou situadas em blocos de vegetação adaptados de Rocha et al. (2003) (Fig. 2). Os autores supracitados definiram cinco blocos de vegetação, aos quais aqui se acrescentam mais dois: Região dos Lagos e Central Sul (Tabela 1). As duas propostas consideradas em conjunto permitem uma visão mais completa. A primeira busca uma divisão detalhada em municípios, permitindo localizar 
individualmente cada exemplar examinado e evidencia a situação atual de conservação e ameaça de cada um deles, agrupando-os em regiões econômicas. Já a segunda, contribui com a visão atual da cobertura vegetal no estado.

Para a análise de similaridade entre os blocos de vegetação foi feita uma matriz de presença e ausência das espécies. Utilizou-se o programa BioDiversity Pro Versão 2/1997 (The Natural History Museum \& Scottish Association for Marine Science) para o cálculo do índice de similaridade de Jaccard (Tabela 2) e para gerar um dendrograma utilizando-se a média do grupo (Fig. 3).

Os grupos de ocorrência das espécies foram determinados através da análise da presença e ausência em cada bloco de vẹretação (Tabela 3). O padrão de distribuição amplo é definido para espécies com ocorrência em mais de um bloco de vegetação e o padrão restrito, para espécies que ocorrem em apenas um bloco de vegetação.

A distribuição global apresentada para as espécies foi definida através dos dados em Bathlott \& Taylor (1995) e Taylor (2000). Os trabalhos de Zappi (1994), Mc Millan \& Horobin (1995) e Taylor \& Zappi (2004) forneceram dados complementares de distribuição (Tabela 4).

As informações sobre a ocorrência em unidades de conservação, o hábito e o hábitat das espécies foram obtidas através de anotações contidas nas etiquetas dos exemplares examinados. Em complementação, foram realizadas várias coletas por todo o estado, que contribuíram com diversas informações relevantes. Também foi consultada a listagem preliminar de espécies da restinga (www.restinga.net).

Para determinar o estado de conservação das espécies foram utilizados as categorias e critérios estabelecidos pela IUCN (2001). Os trabalhos de Mendonça \& Lins (2000) e de Forzza et al. (2003) foram consultados para maior esclarecimento quanto à aplicação dos critérios. As categorias da IUCN versão
3.1 (2001) apresentadas são: DD - sem dados, NE - não avaliada, LC - não ameçada, NT quase ameaçada, VU - vulnerável, EN ameaçada e CR - criticamente ameaçada.

Os estados de conservação das espécies para o leste do Brasil e/ou floresta atlântica brasileira foram obtidos dos trabalhos de Taylor (1997, 2000, 2001), sendo que foi adotada a avaliação mais recente para cada espécie. Taylor (1997, 2000) utiliza as categorias definidas pela IUCN (1994) listadas a seguir: DD - sem dados, NT - não ameaçada, CD - dependente de Conservação, LR - pouco risco, EN - ameaçada, EW - extinta no ambiente natural.

\section{Resultados e Discussão}

Schumann (1890) listou 35 espécies e dez gêneros de Cactaceae para o Rio de Janeiro. Löfgren (1915, 1918), ao estudar Rhipsalis, reconheceu 54 espécies, das quais 34 ocorrem no estado, sendo oito novas espécies descritas por ele à partir de exemplares do Rio de Janeiro. Chaves para identificação e dados taxonômicos sobre 23 espécies, subordinadas a nove gêneros, foram publicados por Castellanos (1961, 1962, 1963, 1964).

Os estudos mais recentes sobre a taxonomia da família no estado do Rio de Janeiro foram realizados por Freitas (1990/1992, 1996, 1997), abrangendo a Área de Proteção Ambiental de Massambaba, a Reserva Ecológica de Macaé de Cima e a Área de Proteção Ambiental Cairuçu, respectivamente.

Scheinvar et al. (1996) publicaram um estudo para o município do Rio de Janeiro, compreendendo 15 espécies e oito gêneros para a área da Reserva Florestal da Vista Chinesa.

\section{Riqueza de espécies}

Para o estado do Rio de Janeiro são apontadas 45 espécies subordinadas a 13 gêneros (Tabela 4). Destaca-se o gênero Rhipsalis como o mais representativo com 23 espécies (52\% do total de espécies). Em seguida Schlumbergera com cinco (12\%), Lepismium e Pilosocereus com três cada (7\%), Hatiora e Pereskia com duas cada 
Tabela 2 - Valores (\%) de similaridade florística das espécies de Cactaceae entre os blocos de vegetação do estado do Rio de Janeiro. Os maiores valores estão em negrito e os menores sublinhados.

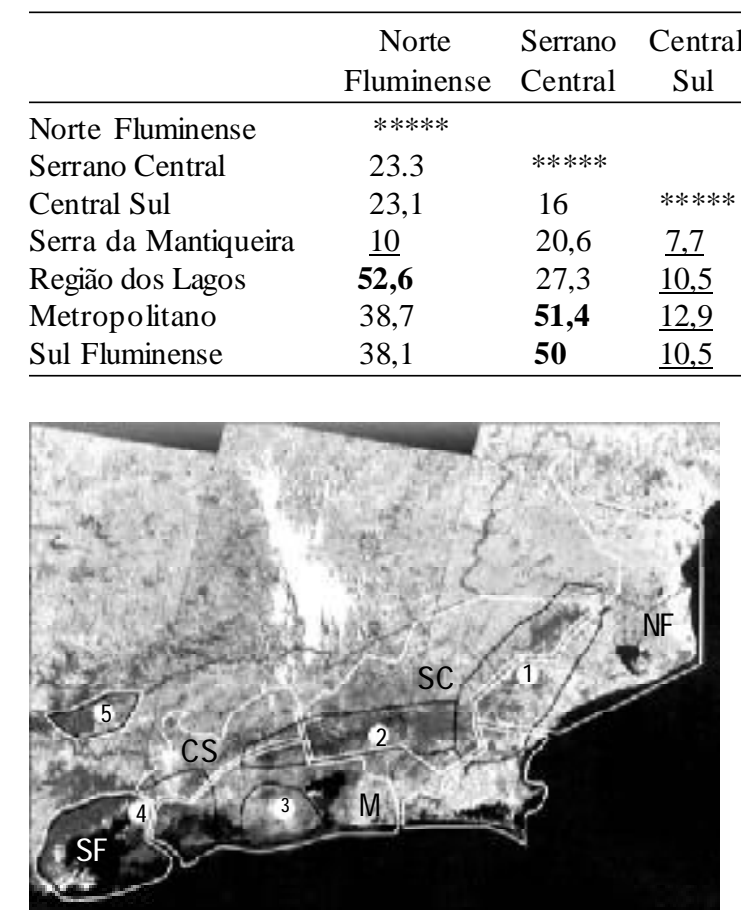

Figura 2 - Imagem de satélite do estado do Rio de Janeiro com a delimitação dos blocos de remanescentes de vegetação determinados por Rocha et al. 2003 (contorno preto, numerados de 1 a 5). A adaptação utilizada no presente trabalho está representada pelos contornos brancos e pelas abreviaturas dos blocos. 1- Norte Fluminense (NF), 2- Serrano Central (SC), 3- Metropolitano (M), 4Sul Fluminense (SF), 5- Serra da Mantiqueira (SM), Central Sul(CS) e Região dos Lagos (RL).

(4\%) e, por fim, Brasiliopuntia, Cereus, Coleocephalocereus, Epiphyllum, Melocactus, Hylocereus e Opuntia que apresentam uma espécie cada um (2\%) (Fig. 4).

Do total de espécies listadas 35 (77\%) são endêmicas para o leste brasileiro e/ou floresta atlântica brasileira, sendo que 21 pertencem a Rhipsalis. O gênero Schlumbergera é endêmico desta região (Mc Millan \& Horobin, 1995), assim como as três espécies de Pilosocereus (Tabela 4).

As sete espécies que ocorrem exclusivamente no estado do Rio de Janeiro pertencem aos gêneros Rhipsalis (4 spp.), Schlumbergera (2 spp.) e Pilosocereus (1 sp.) (Tabela 4).

\begin{tabular}{|c|c|c|c|}
\hline $\begin{array}{c}\text { Serra da } \\
\text { Mantiqueira }\end{array}$ & $\begin{array}{l}\text { Região } \\
\text { dos Lagos }\end{array}$ & Metropolitano & $\begin{array}{c}\text { Sul } \\
\text { Fluminense }\end{array}$ \\
\hline$* * * * *$ & & & \\
\hline$\underline{8}$ & $* * * * *$ & & \\
\hline$\underline{\overline{3}, 9}$ & 45,5 & $* * * * *$ & \\
\hline$\overline{12,5}$ & 41,7 & 54,8 & $* * * * *$ \\
\hline
\end{tabular}

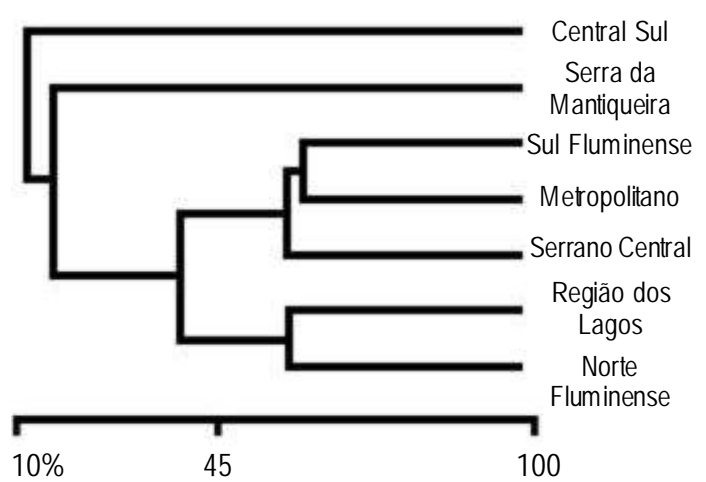

de similaridade

Figura 3 - Dendrograma ilustrando a similaridade florística entre os blocos de vegetação com base na ocorrência das espécies de Cactaceae no estado do Rio de Janeiro.

\section{Distribuição geográfica no estado do Rio de Janeiro}

Foram encontrados exemplares da família Cactaceae em 36 municípios distribuídos por todas as regiões do estado. Apesar da grande pressão antrópica, o município do Rio de Janeiro é o de maior riqueza (30 spp.). Outros municípios também apresentam uma alta diversidade principalmente aqueles que contêm unidades de conservação como Macaé, Nova Friburgo, Petrópolis, Teresópolis, Saquarema, Niterói, Parati e Angra dos Reis (Tabela 1).

O bloco com maior número de espécies (31 spp./68\%) é o Metropolitano, sendo que nele ocorrem todos os gêneros listados para o estado. O bloco Serrano Central apresenta 25 espécies (56\%) e seis gêneros (46\%). Os blocos Sul Fluminense e Região dos Lagos possuem 17 espécies cada (38\%), sendo que no primeiro ocorrem oito gêneros (62\%) e no segundo 11 (85\%). Para o Norte Fluminense estão listadas 12 espécies (26\%) subordinadas a nove 
Tabela 3 - Padrões de distribuição das espécies de Cactaceae com base nos grupos de ocorrência estabelecidos para o estado do Rio de Janeiro.

\begin{tabular}{|c|c|c|}
\hline $\begin{array}{c}\text { Padrão de } \\
\text { dis tribuição }\end{array}$ & Grupos de ocorrência & Espécies \\
\hline \multirow[t]{21}{*}{ Amplo } & $\begin{array}{l}\text { 1. Norte Fluminense / Serrano Central / Serra da } \\
\text { Mantiqueira / Região dos Lagos / Metropolitano/ } \\
\text { Sul Fluminense }\end{array}$ & Pereskia aculeata \\
\hline & 2. Norte Fluminense / Serrano Central / Central Sul / & Epiphyllum phyllanthus $\mathrm{e}$ \\
\hline & $\begin{array}{l}\text { Região dos Lagos / Metropolitano / } \\
\text { Sul Fluminense }\end{array}$ & Rhipsalis lindbergiana \\
\hline & $\begin{array}{l}\text { 3. Serrano Central/ Serra da Mantiqueira/ Região dos } \\
\text { Lagos / Metropolitano / Sul Fluminense }\end{array}$ & Rhipsalis pachyptera \\
\hline & $\begin{array}{l}\text { 4. Norte Fluminense / Serrano Central / Serra da } \\
\text { Mantiqueira/ Metropolitano / Sul Fluminense }\end{array}$ & Rhipsalis floccosa \\
\hline & $\begin{array}{l}\text { 5. Norte Fluminense / Serrano Central / Região dos } \\
\text { Lagos / Metropolitano / Sul Fluminense }\end{array}$ & Lepismium cruciforme e Rhipsalis teres \\
\hline & $\begin{array}{l}\text { 6. Serrano Central / Região dos Lagos / Metropolitano / } \\
\text { Sul Fluminense }\end{array}$ & Hylocereus setaceus e Rhipsalis oblonga \\
\hline & $\begin{array}{l}\text { 7. Serrano Central / Central Sul / Serra da Mantiqueira / } \\
\text { Metropolitano }\end{array}$ & Lepismium houlletianum \\
\hline & $\begin{array}{l}\text { 8. Norte Fluminense / Região dos Lagos / Metropolitano / } \\
\text { Sul Fluminense }\end{array}$ & $\begin{array}{l}\text { Cereus fernambucensis e } \\
\text { Opuntia monacantha }\end{array}$ \\
\hline & $\begin{array}{l}\text { 9. Norte Fluminense / Serrano Central / Central Sul / } \\
\text { Metropolitano }\end{array}$ & Pereskia grandifolia \\
\hline & 10. Serrano Central / Metropolitano / Sul Fluminense & $\begin{array}{l}\text { Hatiora salicornioides, } \\
\text { Rhipsalis clavata, } R \text {. elliptica, } \\
R . \text { neves-armondii e } R \text {. paradoxa }\end{array}$ \\
\hline & 11. Serrano Central / Serra da Mantiqueira/ Metropolitano & Rhipsalis pulchra \\
\hline & 12. Norte Fluminense / Região dos Lagos / Metropolitano & Brasiliopuntia brasiliensis, \\
\hline & & Melocactus violaceus $\mathrm{e}$ \\
\hline & & Pilosocereus brasiliensis \\
\hline & 13. Metropolitano / Sul Fluminense & Rhipsalis grandiflora \\
\hline & 14. Região dos Lagos / Metropolitano & $\begin{array}{l}\text { Coleocephalocereus fluminensis } \\
\text { e Pilosocereus arrabidae }\end{array}$ \\
\hline & 15. Serrano Central / Metropolitano & Rhipsalis campos-portoana $\mathrm{e}$ \\
\hline & & Schlumbergera truncata \\
\hline & 16. Serrano Central / Serra da Mantiqueira & Rhipsalis pilocarpa \\
\hline & 17. Serrano Central/ Região dos Lagos & Rhipsalis crispata \\
\hline \multirow[t]{4}{*}{ Restrito } & 18. Serrano Central & $\begin{array}{l}\text { Rhipsalis ewaldiana, } R \text {. olivifera, } \\
R . \text { ormindoi e Schlumbergera russelliana }\end{array}$ \\
\hline & 19. Serra da Mantiqueira & $\begin{array}{l}\text { Hatiora epiphylloides, Rhipsalis cereuscula, } \\
\text { Schlumbergera microsphaerica } \\
\text { e S. opuntioides }\end{array}$ \\
\hline & 20. Região dos Lagos & Pilosocereus ulei \\
\hline & 21. Metropolitano & $\begin{array}{l}\text { Rhipsalis cereoides, } R \text {. mesembryanthemoides, } \\
R \text {. pentaptera e } R \text {. puniceodiscus }\end{array}$ \\
\hline
\end{tabular}

gêneros (69\%) e, para a Serra da Mantiqueira, dez espécies (22\%) em cinco gêneros (38\%). O bloco Central Sul é o que apresenta menor riqueza, com quatro gêneros $(30 \%)$ e quatro espécies (9\%) (Tabela1).

Rhipsalis é o gênero mais representativo em todos os blocos. A maior riqueza encontrada foi no bloco Serrano Central, onde $72 \%$ (18 spp.) das espécies que lá ocorrem pertencem a esse gênero. No bloco Norte Fluminense (3 spp.) e no Central Sul (1 sp.) foi encontrada a menor riqueza, apenas $25 \%$ das espécies que lá ocorrem pertencem a Rhipsalis. 


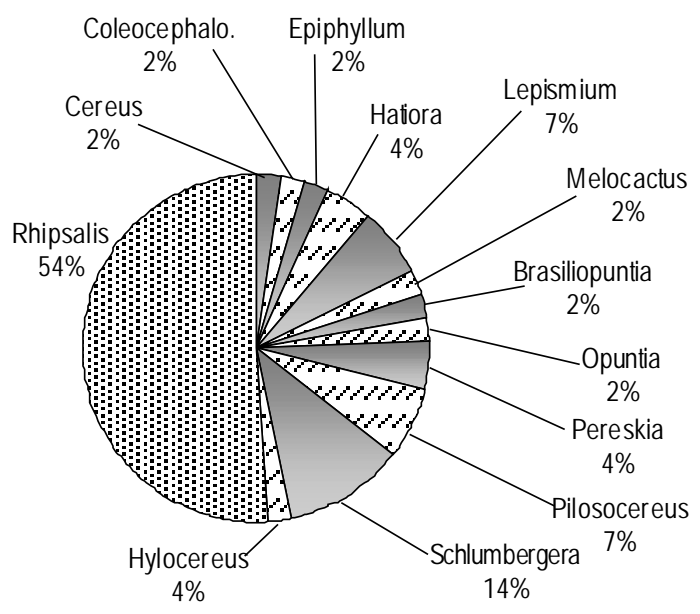

Figura 4 - Riqueza dos gêneros (\%) de Cactaceae ocorrentes no estado do Rio de Janeiro

Outros gêneros com particular representatividade são Pilosocereus, na Região dos Lagos (3spp./ 18\% das espécies que lá ocorrem) e Schlumbergera, na Serra da Mantiqueira (2 spp./20\%)

$\mathrm{Na}$ figura 3 está representada a similaridade entre os blocos de vegetação (Tabela 2). Foi encontrada uma similaridade alta entre os blocos Sul Fluminense e Metropolitano e entre os blocos Norte Fluminense e Região dos Lagos, demonstrando uma subdivisão norte-sul da riqueza de Cactaceae no litoral do estado, que tem seu limite na divisa dos blocos Metropolitano e Região dos Lagos. O bloco Serrano Central apresentou-se mais similar aos blocos do sul do estado, fato que pode ser sustentado pelo predomínio da floresta pluvial atlântica nesses blocos, em contraste com as grandes áreas dominadas por restinga nos blocos do litoral norte.

O bloco Central Sul mostra pouca similaridade com os demais, provavelmente devido ao pequeno número de coletas que caracterizam a sua área. Ainda assim, esse bloco está mais relacionado com o Norte Fluminense e o Serrano Central. O bloco da Serra da Mantiqueira também apresenta pouca similaridade com os demais, porém, está mais relacionado com o Serrano Central com o qual se assemelha por características físicas como altitude e clima, descritos por Rocha et al. (2003) (Tabela 2).
Foram identificados, com base na análise da ocorrência das espécies nos blocos de vegetação, 21 grupos (Tabela 3). As espécies Lepismium warmingianum, Rhipsalis pacheco-leonis e Schlumbergera orssichiana não foram incluídas na análise, em virtude da insuficiência de dados amostrais.

Epiphyllum phyllanthus, Hylocereus setaceus, Lepismium cruciforme, Pereskia aculeata, Rhipsalis floccosa, $R$. lindbergiana, $R$. oblonga, $R$. pachyptera e $R$. teres são espécies que apresentam um padrão amplo, com ocorrência em pelo menos cinco blocos de vegetação.

Os grupos de ocorrência 8, 12, 14 e 19 (Tabela 3) evidenciam a distribuição litorânea de espécies típicas da restinga. $\mathrm{O}$ bloco Metropolitano é o limite sul da distribuição global de Coleocephalocereus fluminensis, Melocactus violaceus, Pilosocereus arrabidae e Pilosocereus brasiliensis, enquanto Cereus fernambucensis e Opuntia monacantha estendem-se até o sul do Estado. Rhipsalis grandiflora apresenta como o limite norte de sua distribuição global o bloco Metropolitano. O mesmo acontece com Rhipsalis puniceodiscus, sendo este fato uma provável justificativa para suas raras ocorrências.

As espécies com padrão restrito pertencem aos gêneros Hatiora, Pilosocereus, Rhipsalis e Schlumbergera e estão presentes nos blocos Serrano Central, Serra da Mantiqueira, Região dos Lagos e Metropolitano. O bloco Serra da Mantiqueira merece destaque, pois $40 \%$ (4 spp.) das espécies que lá ocorrem apresentam padrão de distribuição restrito. Entre as espécies com padrão restrito, 85\% (6 spp.) ocorrem em localidades ou áreas limitadas dentro dos blocos (Tabelas 3 e 4). Isso demonstra a necessidade de cuidado para a sua conservação.

Rhipsalis cereuscula, embora possua uma distribuição global ampla no leste do Brasil, no estado apresenta padrão restrito ocorrendo somente na Serra da Mantiqueira, assim como Rhipsalis pilocarpa que só ocupa, com evidência de poucos exemplares, os blocos 
Serrano Central e Serra da Mantiqueira (Tabelas 3 e 4). Isto é uma indicação de uma alta taxa de diminuição no hábitat dessas espécies. O mesmo pode ser interpretado no caso de Lepismium warmingianum, do qual não constam exemplares.

\section{Hábitat}

Na tabela 5 são apresentados os dados comparativos sobre a distribuição da família nos diferentes hábitats. A floresta pluvial atlântica, que é a cobertura vegetal predominante no estado, contém o maior número de espécies exclusivas (23 spp./ 51\%). Destaca-se o gênero Schlumbergera (5 spp.) que só ocorre neste hábitat. Rhipsalis é o que apresenta maior riqueza, com 15 espécies, enquanto Lepismium possui duas e Hatiora apenas uma.

Entre as espécies exclusivas da floresta pluvial atlântica 12 encontram-se nas categorias de ameaçadas ou quase ameaçadas, reforçando a necessidade de preservação desse hábitat.

Onze gêneros e 20 espécies (44\% do total) ocorrem tanto na restinga quanto na floresta pluvial atlântica, demonstrando que a família está bem representada nas diferentes formações vegetais do estado e evidenciando que essas espécies possuem alta variabilidade e capacidade adaptativa.

Na restinga, são encontradas apenas duas espécies exclusivas, Melocactus violaceus e Pilosocereus ulei, sendo que ambas são consideradas ameaçadas devido ao crescimento de áreas urbanas e conseqüente diminuição de seu hábitat naturalmente restrito.

Algumas espécies, como Pilosocereus brasiliensis e Cereus fernambucensis, são usualmente conhecidas como características da restinga, entretanto são listadas também para a floresta pluvial atlântica, pois ocorrem em afloramentos rochosos como rupícolas. Este fato está relacionado com as condições ambientais como o estresse hídrico, alta irradiação solar e até mesmo a salinidade que ocorrem de forma semelhante na restinga e nos afloramentos rochosos.
Nos blocos considerados neste trabalho a maior representatividade é das espécies comuns à restinga e à floresta pluvial atlântica, com exceção da Serra da Mantiqueira onde a maior riqueza ( $7 \mathrm{spp} . / 70 \%$ do total de espécies ocorrentes no bloco) é de espécies exclusivas da floresta pluvial atlântica.

O Metropolitano é o único bloco que apresenta espécies comuns (19 spp./61\%) e exclusivas de cada hábitat (11 spp./36\% floresta pluvial atlântica e $1 \mathrm{sp} . / 3 \%$ - restinga), o que pode ser explicado pela heterogeneidade ambiental dentro dos seus limites, que se reflete na alta riqueza de espécies que apresenta.

\section{Conservação}

Neste trabalho Coleocephalocereus fluminensis, Melocactus violaceus, Rhipsalis mesembryanthemoides e Schlumbergera truncata são listadas como vulnerável, ameaçada, vulnerável e quase ameaçada para o estado, respectivamente (Tabela 4). Costa (2000) apresenta estas espécies como ameaçadas de extinção para o município do Rio de Janeiro.

Oito espécies foram aqui definidas como quase ameaçadas para o estado, entre elas cinco espécies de Rhipsalis, uma de Hatiora, uma de Lepismium e outra de Pilosocereus (Tabela 4).

Para o estado do Rio de Janeiro, Coleocephalocereus fluminensis, Pilosocereus arrabidae, Schlumbergera opuntioides e Schlumbergera russelliana são aqui enquadradas como vulneráveis. Em Taylor (1997, 2001) elas estão listadas respectivamente, como de baixo risco, sem dados, quase ameaçada e dependente de conservação.

Melocactus violaceus, Rhipsalis mesembryanthemoides e Pilosocereus ulei são categorizadas como espécies ameaçadas no estado, sendo que $R$. mesembryanthemoides é endêmica da Região Metropolitana e P. ulei da Região dos Lagos. As três espécies sofrem com a redução e alteração dos seus hábitats devido à urbanização acelerada. Isto provoca a redução de suas populações e a perda de diversidade genética, colocando a existência 
dessas em grande risco. O caso de $P$. ulei é muito grave já que ocorre em uma área restrita cujo microclima é diferente do restante da costa brasileira. Esta área não se encontra protegida por unidades de conservação e vem sendo reduzida rapidamente devido à localização litorânea, que possui alto valor frente ao mercado imobiliário.

Rhipsalis pentaptera está listada em Taylor (1997) como "extinta no ambiente natural", aqui, no entanto, ela foi considerada como "criticamente em perigo", pois ainda ocorre, em uma localidade, dentro da área urbana do município do Rio de Janeiro.

Dez espécies (Tabela 4) não possuem seus estados de conservação definidos para o estado do Rio de Janeiro por falta de dados, evidenciando a necessidade de estudos mais aprofundados em relação à sua ocorrência. São elas: Hatiora epiphylloides, Lepismium warmingianum, Rhipsalis crispata, $R$. ewaldiana, $R$. olivifera, $R$. ormindoi, $R$. pacheco-leonis, $R$. puniceodiscus, Schlumbergera microsphaerica e $S$. orssichiana.

A maioria das espécies aqui listadas está representada dentro e fora de unidades de conservação, entretanto, é importante ressaltar que o adequado manejo dessas unidades é fundamental para a sobrevivência $d$ as populações, principalmente daquelas espécies definidas como vulneráveis ou ameaçadas.

Taylor (1997) relata que as maiores pressões sofridas pelas populações naturais de cactos são, em ordem crescente de severidade: (1) desenvolvimento agrícola e desmatamento; (2) urbanização e desenvolvimento de infraestrutura como construções de estradas e hidrelétricas; (3) extrativismo para cultivo; (4) mineração atingindo táxons que habitam especificamente afloramentos de granitos ou outras rochas.

Para o estado do Rio de Janeiro a principal ameaça é a pressão antrópica que se expressa das formas mais variadas, incluindo as listadas acima. É importante mencionar fatores que colocam em risco a sobrevivência das populações naturais, como a urbanização crescente e a especulação imobiliária que vem provocando a ocupação desordenada da restinga e das áreas florestais litorâneas.

Além desses, outros impactos como as queimadas, potencializadas por espécies de gramíneas invasoras, comuns nos afloramentos rochosos, ameaçam as espécies rupícolas. Um elevado grau de endemismo foi observado por Meirelles et al. (1999) para a vegetação dos afloramentos rochosos do Rio de Janeiro, incluindo as Cactaceae. Os mesmos autores afirmam que devido à fragilidade de tais ambientes e vulnerabilidade a que as comunidades vegetais estão expostas, ações conservacionistas que contemplem esses hábitats são urgentes.

Visto esse quadro de ameaça, novas propostas e medidas efetivas de preservação e conservação dos hábitats naturais, ricos em espécies de Cactaceae devem ser tomadas, principalmente a criação de unidades de conservação junto ao litoral. Além disso, novos estudos de campo, taxonômicos e ecológicos dessas espécies são importantes para uma maior compreensão da ocorrência da família no estado.

Tabela 5 - Relação entre o número de gêneros e espécies da família Cactaceae por hábitats e estados de conservação no estado do Rio de Janeiro. Os maiores valores encontrados estão em negrito.

\begin{tabular}{lcccc}
\hline Hábitat Gêneros Espécies & $\begin{array}{c}\text { Ameaçadas/ } \\
\text { quase } \\
\text { ameaçadas }\end{array}$ & $\begin{array}{c}\text { Sem } \\
\text { dados de } \\
\text { conservação }\end{array}$ \\
\hline $\begin{array}{l}\text { Floresta } \\
\text { Pluvial }\end{array}$ & 1 & $\mathbf{2 3}$ & $\mathbf{1 2}$ & $\mathbf{9}$ \\
$\begin{array}{l}\text { Atlântica } \\
\text { (exclusivos) }\end{array}$ & & & & \\
$\begin{array}{l}\text { Restinga } \\
\text { (exclusivos) }\end{array}$ & 1 & 2 & 2 & - \\
Ambos & $\mathbf{1 1}$ & $\mathbf{2 0}$ & 4 & 1 \\
\hline
\end{tabular}


Tabela 4 - Lista de espécies, hábito, hábitat, distribuição geográfica e estado de conservação das espécies de Cactaceae no Rio de Janeiro. Avaliação global para o leste do Brasil e/ou floresta atlântica brasileira $(*=$ endêmicas) segundo Taylor $(1997,2000,2001)$, para o estado do Rio de Janeiro (**=endêmicas) aqui determinadas e para o município do Rio de Janeiro, quando avaliadas, segundo Costa (2000). Categorias (IUCN, 1994, 2001) - NE: não avaliada; DD: sem dados;LC ou nt: não ameaçada; CD: dependente de conservação; LR: pouco risco; NT: quase ameaçada; VU: vulnerável; EN: ameaçada; CR: críticamente ameaçada;EW: extinta no ambiente natural. Distribuição no Brasil indicada pela sigla dos estados.

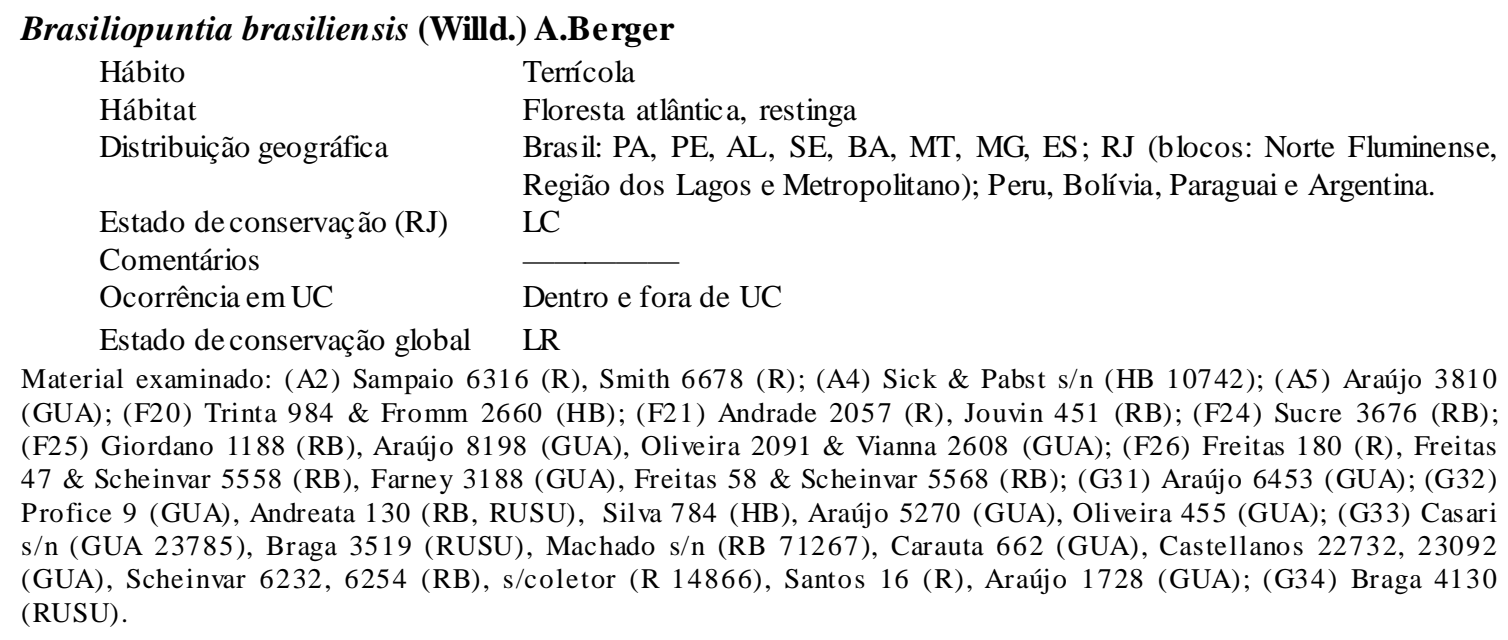

*Cereus fernambucencis Lem.

Hábito

Hábitat

Terrícola, rupícola

Restinga, floresta atlântica

Distribuição geográfica

Estado de conservação (RJ) Região dos Lagos, Metropolitano e Sul Fluminense).

Comentários

Ocorrência em UC Dentro e fora de UC

Estado de conservação global LR

Material examinado: (A2) Sampaio 6268 (R); (A5) Pereira 18 (HB), Pinheiro 113 (HB); (F23) Przewodowski \& Vassilion s/n (RB 216072); (F24) Farney 2239 (RB), Monteiro s/n (RBR 5281), Monteiro 4083 (RBR); (F25) Freitas 51a \& Scheinvar 5561a (RB), Giordano 1189 (RB); (F26) Freitas 57 (RB); (G31) Freitas 28 \& Scheinvar 5540 (RB), Freitas 33 \& Scheinvar 5545 (RB); (G33) Scheinvar 1303, 6231, 6281 (RB), Scheinvar s/n (RB 168900), Machado s/n (RB 71266), Almeida 1321 (RB), s/coletor (RB 193675), Brade 20082 (RB), Duarte 4659 (RB), s/coletor (RB 193674), Rizzini 306 (RFA); (H35) Giordano 272 \& Martins 45 (RB); (H36) Brade s/n (R), Freitas 161, 163 $(\mathrm{RB})$.

\section{*Coleocephalocereus fluminensis (Miq.) Backeb.}

Hábito

Hábitat

Distribuição geográfica

Estado de conservação (RJ)

Comentários

Ocorrência em UC

Estado de conservação global

\section{Rupícola}

Restinga, floresta atlântica

Brasil: MG, ES e RJ (blocos: Região dos Lagos e Metropolitano).

VU/ameaçada

Populações restritas aos afloramentos rochosos. Sofre redução do seu hábitat devido à grande pressão antrópica (urbanização intensa, especulação imobiliária e queimadas).

Dentro e fora de UC

LR

Material examinado: (F25) Segadas-Vianna 4037 (R); (G32) Andreata 889 (RUSU); (G33) Castellanos 22395 (HB), Cardoso 413 (R), Braga 3342 (RUSU), Scheinvar 6228 (RB), Santos 5812 (R), Marquete 599 (RB) 
Epiphyllum phyllanthus (L.)Haw.

Hábito
Hábitat
Distribuição geográfica

Estado de conservação (RJ)

Comentários

Ocorrência em UC

Epífita, rupícola

Restinga, floresta atlântica

Ocorre amplamente na região neotropical. No RJ (blocos: Norte Fluminense, Serrano Central, Central Sul, Região dos Lagos, Metropolitano e Sul Fluminense). LC

Estado de conservação global

Dentro e fora de UC

LR

Material examinado: (A2) Araújo 8897 (GUA); (C11) Scheinvar 6320 (RB); (D15) Scheinvar 6317 (RB); (F24) Araújo 3054, 10324 (GUA); (G32) Silva 336 (GUA); (G33) Scheinvar 6258, 6266 (RB), Castellanos 23166 (R) Castellanos 22393 (GUA), Menezes 694 (RBR); (G34) Braga 3585 (RUSU); (H35) Araújo 4161, 6494, 9036 (GUA); (H36) Araújo 3617, 3620 (GUA), Feitas 95 (RB).

\section{*Hatiora epiphylloides (Campos-Porto \& Werdermann) Buxb.}

Hábito

Hábitat

Distribuição geográfica

Estado de conservação (RJ)

Comentários

Ocorrência em UC

Estado de conservação global
Rupícola, epífita

Floresta atlântica

Brasil: RJ (Ocorre na Região da Serra da Mantiqueira, segundo a bibliografia) e SP. DD

Não foram encontrados exemplares. Provável ameaçada.

Sem dados

EN

\section{*Hatiora salicornioides (Haw.) B ritton \& Rose}

Hábito

Hábitat

Distribuição geográfica

Estado de conservação (RJ)

Comentários

Ocorrência em UC

Estado de conservação globa
Rupícola, epífita

Floresta atlântica, restinga

Brasil: BA, MG, ES, RJ (blocos: Serrano Central, Metropolitano e Sul Fluminense), SP e PR.

LC

Dentro e fora de UC

LR

Material examinado: (B8) Capell s/n (FACB 709); (C11) Brade 14415 (R), Castellanos 24580 (GUA), Lutz 35 (R), Pereira 264 (RB), Martinelli 3320 (RB), Cardoso 152 (R ), Barros 1073 (RB); (C12) Sampaio 7702 (R), Sucre 10585 (RB), Sucre 3475 \& Braga 1053 (RB), Martinelli 104, 1552, 1587, 1806, 5780 (RB), Smith 6481 (R), Scheinvar 6342 (RB), Campos Goes \& Constantino s/n (RB 49529); (G28) Lima 2307 (R); (G33) Brade 11036 (R), Castellanos 23361 (GUA), Oliveira 1835 (GUA), Angeli 267 (GUA), Araújo 401 (RB), Pedrosa 948 (GUA), Sucre 9514, 10053 (RB), Sucre 3534 \& Braga 1078 (RB), Martinelli 4880 (RB), Glaziou 461 (R), Braga 3642 (RUSU), Saldanha 8582 (R), Neto s/n (R 91033), Landrum 2200 (RB), Scheinvar 6260, 6267 (RB), Marquete 607, 1037, 2809 (RB), s/coletor (R 78693), Schwacke s/n (R 101494), Ferreira 3370 (GUA); (H35) Ribeiro 1821 (GUA); (H36) Oliveira 301 \& Vianna 985 (GUA).

\section{Hylocereus setaceus (Salm-Dyck ex DC.) Ralf Bauer}

Hábito

Hábitat

Distribuição geográfica

Estado de conservação (RJ)

Comentários

Ocorrência em UC
Rupícola, epífita

Floresta atlântica, restinga

Brasil: RR, PA, MA, PI, PE, AL, SE, BA, MG, ES, RJ (blocos: Serrano Central, Região dos Lagos, Metropolitano e SulFluminense), SP, PR; Bolívia, Paraguai e Argentina.

LC

Dentro e fora de UC

LR

Material examinado: (C12) Scheinvar 6345a (RB); (F21) Vilaça 95 (GUA); (F26) Freitas 46 \& Scheinvar 5577 (RB), Araújo 8379 (GUA); (G31) Scheinvar 6288 (RB), Pabst s/n (HB 28755), Araújo 5752, 5928, 6449 (GUA), Botelho 509 (GUA), Freitas 31, 39, 40 (RB; (G32) Scheinvar 6291 (RB); (G33) Castellanos 23203 (R), Sucre 7928 (RB), Guimarães 72 (RB), Cardoso 416 (R), Menezes 454 (RBR), Souza 212 (RBR), Machado s/n (RB 75249), Ribeiro 216 (GUA), Scheinvar 1306, 6233, 6237, 6250, 6273, 6277, 6278, 6328, 6331, 6336 (RB); (G34) Braga 3438 (RUSU); (H35) Araújo 5850 (GUA); (H36) Freitas 79, 156 (RB). 


\section{Lepismium cruciforme (Vell.) Miq.}

Hábito
Hábitat
Distribuição geográfica
Estado de conservação (RJ)
Comentários
Ocorrência em UC
Estado de conservação global

Terrícola, epífita

Floresta atlântica, restinga

Brasil: PE, BA, MG, MS, ES, RJ (blocos: Norte Fluminense, Serrano Central, Região dos Lagos, Metropolitano e Sul Fluminense), SP, PR, SC, RS; Paraguai. LC

Dentro e fora de UC

LR

Material examinado: (A5) Araújo 8643 (GUA); (B7) Armond 197, 336, 340 (R); (C11) Castellanos 23520 (GUA); (C12) Glaziou 13916, 14863 (R), Goes \& Dionísio 972 (RB), Smith 6474 (R); (F23) Araújo 9427 (GUA); (F24) Smith 6656 (R); (F26) Martinelli 4505 (RB), Freitas 55 (RB); (G29) Oliveira 387 (GUA), Castellanos 23154, 25624 (GUA); (G31) Araújo 5381, 5404, 6246 (GUA), Araujo 677 (RB), Souza 1865 (R), Giordano 179 (RB), Klein 227 (RB), Freitas 38 \& Scheinvar 5549 (RB); (G33) Castellanos 23611 (GUA), Garke s/n (R 91038), Oliveira 1440 (GUA), Sucre 7388, 10013 (RB), Martinelli 4952 (RB), Scheinvar 6235, 6253, 6278, 6279 (RB), Lad Neto s/n (R 91029), Capell s/n (FCAB 714), Ribeiro 2294 (GUA), Ferreira 255 (RB); (H35) Campos Porto 111 (RB); (H36) Freitas $88,121(\mathrm{RB})$.

\section{*Lepismium houlletianum (Lem.) Barthlott}

Hábito
Hábitat
Distribuição geográfica
Estado de conservação (RJ)
Comentários

\section{Epífita}

Floresta atlântica

Brasil: MG, ES?, RJ (blocos: Serrano Central, Central Sul, Serra da Mantiqueira e Metropolitano), SP, PR, SC, RS; Argentina.

\section{NT}

Característica de ambientes bem preservados. Sofre com a diminuição/ perturbação de seu hábitat natural. Sua ocorrência vem diminuindo no estado.

Ocorrência em UC Dentro e fora de UC

Estado de conservação global LR

Material examinado: (B8) Vieira 286 (RB), Forgaça 51 (RB); (C12) Marques 141 (RB); (D13) Martinelli 4576 (RB); (E18) Sucre 5159 (RB), Martinelli 5715, 9247 (RB), Ferreira 139 (RB); (E19) Brade 14559 (RB), Hunt 6414 (RB), Dunsen s/n (R 91037); (G29) Glaziou 14861 (R); (G33) Brade 11921 (R), Castellanos s/n (GUA 6933), Duarte 4909 (RB), Oliveira 1844 (GUA), Angeli 73 (GUA), Sucre 5061 (RB), Ule s/n (R 91108), Ule 3791 (R), Kuhlmann s/n (RB 19388), Scheinvar 5573, 6257 (RB), Ribeiro 510 (GUA).

\section{Lepismium warmingianum (K. Schum.) Barthlott}

Hábito

Hábitat

Distribuição geográfica

Estado de conservação (RJ)

Comentários

Ocorrência em UC

Estado de conservação global
Epífita

Floresta atlântica

Brasil: PA, MG, MS, ES, RJ, SP, SC, RS; Paraguai e Argentina.

Não foram encontrados exemplares. Provavelmente rara no estado.

Sem dados

LR

\section{*Melocactus violaceus Pfeiff.}

Hábito
Hábitat
Distribuição geográfica
Estado de conservação (RJ)
Comentários

Ocorrência em UC

Estado de conservação global

\author{
Terrícola \\ Restinga \\ Bras il: RN, PB, PE, SE, BA, MG, ES E RJ (blocos: Norte Fluminense, Região \\ dos Lagos e Metropolitano). \\ EN/Ameaçada \\ Provavelmente não ocorre mais na Região Metropolitana. É conhecida na Região \\ Norte Fluminense dentro de UC. Dependente da adequada conservação dos \\ ambientes onde ainda ocorre. \\ Dentro de UC \\ VU
}

Material examinado: (F22) Figueiredo 4 (RB), Freitas 53 (RB); (G33) Castellanos 26706 (HB), Sucre 9186 (RB). 
Opuntia monacantha Haw.

Hábito
Hábitat
Distribuição geográfica
Estado de conservação (RJ)
Comentários
Ocorrência em UC
Estado de conservação global

Terrícola, rupícola

Floresta atlântica, restinga

Brasil: MG, ES, RJ (blocos: Norte Fluminense, Região dos Lagos, Metropolitano e Sul Fluminense); Paraguai, Uruguai e Argentina.

LC

Ocorre cultivada em outros estados.

Dentro e fora de UC

Estado de conservação global

Material examinado: (A2) Sampaio 8000, 8031 (R); (A3) Araújo 4297 (GUA); (F26) Giordano 69 (RB); (G28) Giordano 222, 1247 (RB); (G30) Boudet Fernandes 781 (GUA); (G32) Casari 590 (GUA); (G33) Castellanos 23151, 23844 (GUA), Lima 10 (RB), Angeli 69 (GUA), Rizzini 272 (RFA), Pereira 175 (RFA), Araújo 5358 (GUA), Sucre 7930 (RB), Occhioni 580, Rizzini 394 \& Barros 176 (RFA), Martins 1851 (GUA), Carauta 6763 (GUA), Giordano 230 (RB), Menezes 772 (RBR), Scheinvar 6229, 6282 (RB), s/coletor (RFA 23819), s/coletor (R 9819); (G34) Vianna 830 (R); (H35) Oliveira 365 (GUA), Araújo 4168 (GUA).

\section{Pereskia aculeata Mill.}

Hábito

Hábitat

Distribuição geográfica

Terrícola, rupícola

Floresta atlântica, restinga

México, América Central, Caribe, Brasil: MA, PE, AL, SE, BA, GO, MG, ES, RJ (blocos: Norte Fluminense, Serrano Central, Serra da Mantiqueira, Região dos

Estado de conservação (RJ) Lagos, Metropolitano e Sul Fluminense); Peru, Paraguai, Argentina.

Comentários

Ocorrência em UC $\mathrm{LC}$

Estado de conservação global

Dentro e fora de UC

LR

Material examinado: (A2) Sampaio 8065 (R); (A3) Sampaio s/n (R 135714); (B8) Wendt 56 (RB), Capell s/n (FACB 715); (C10) Pabst 7310 (HB); (C11) Manduca Palma s/n (R 91100); (C12) Campos Goes 67 (RB); (E19) Brade 17435 (RB), Monteiro 1-17-62 (RBR), Campos Porto 1714 (RB); (F21) Jouvin 435 (RB), Martinelli 11653 (RB); (F22) Rizzini 418 (RFA); (F24) Farney 2253 (RB); (F26) Martinelli 4511 (RB), Freitas 219 (R); (G31) Araújo 680, 766 (RB), Freitas 37 \& Scheinvar 5548 (RB), Freitas 42 \& Scheinvar 5553 (RB), Bautista 175 (RB); (G32) Almeida Rego 1010, 1097 (RBR), Pabst s/n (HB 29478), Scheinvar 6290 (RB); (G33) Quinet 2 (RB), Duarte 4806 (RB), Lutz 568 (R), Araújo 3819 (GUA), Sucre 3611, 4940 (RB), Sucre 2623 \& Braga 464 (RB), Freire 611 (R), Glaziou 18267 (R), Rodrigues 75 (RB), Cabral 12 (R), Almeida 1333 (RB), Braga 3320 (RUSU), Lanna Sobrinho s/n (GUA 7131), Khulmann s/n (RB 15850), Giordano 1667 (GUA), Dan 307 (R), Mautone 655 (RB), Scheinvar 6234, 6261, 6272, 6326 (RB), Scheinvar 112 (R), Souza 194 (RBR), Machado 63 (RB), Araújo 245 (RB), Marquete 1170 (RB), Santiago 48 (RB), s/coletor (RB 138788), Trinta 535 \& Fromm 1611 (HB); (G34) Bovini 1058, 1659 (RUSU); (H35) Araújo 6183 (GUA); (H36) Freitas 85 (RB), Martinelli 11383 (RB).

\section{Pereskia grandifolia Haw.}

\section{Hábito \\ Hábitat \\ Distribuição geográfica}

Estado de conservação (RJ)

Comentários

Ocorrência em UC

Estado de conservação global
Terrícola, rupícola

Floresta atlântica, restinga

Introduzid a amplamente na região neotropical. Brasil: CE, PE, BA, MG, MT ES, RJ (blocos: Norte Fluminense, Serrano Central, Central Sul e Metropolitano), SP e SC.

LC

Sua ocorrência espontânea no Estado é duvidosa por ser muito cultivada.

Dentro e fora de UC

$\mathrm{DD}$

Material examinado: (A1) Sampaio 985 (R); (A2) Sampaio 8215 (R); (A3) Trinta 1051 \& Fromm 2127 (HB); (C11) Vellozo 375 (R); (C12) Campos Góes 344, 1034 (RB); (D17) Ferreira 348 (RB); (G33) Lutz 15701 (R), Pabst 5423 (HB), Glaziou 18268 (R), Groth s/n (R 91063), Cabral 3 (R), Khulmann 6188 (RB), Lannasoti 15 (R), Giordano 212 (RB), Freitas 199 (RB). 


\section{*Pilosocereus arrabidae (Lem.) Byles \& Rowley}

$\begin{array}{ll}\text { Hábito } & \text { Terrícola, rupícola } \\ \text { Hábitat } & \text { Floresta atlântica, restinga } \\ \text { Distribuição geográfica } & \text { Brasil: BA, ES e RJ (blocos: Região dos Lagos e Metropolitano). } \\ \text { Estado de conservação (RJ) } & \text { NT } \\ \text { Comentários } & \text { Hábitat natural sofrendo grande pressão antrópica. } \\ \text { Ocorrência em UC } & \text { Dentro e fora de UC } \\ \text { Estado de conservação global } & \text { NT }\end{array}$

Material examinado: (F24) Farney 2274 (RB); (F25) Oliveira 2093 \& Vianna 2610 (GUA), Barroso 13 (RB), Freitas 51 \& Scheinvar 5561 (RB); (G31) Freitas 29 (RB), Freitas 27 \& Scheinvar 5539 (RB), Freitas 30 \& Scheinvar 5542 (RB); (G32) Ferreira 467 (RB); (G33) Castellanos 22442 (R), Sucre 5307 (RB), Pabst 5677 (HB), Carauta 3347 (GUA), Menezes 453 (RBR), Scheinvar s/n (RB 193676), Scheinvar 1305 (RB), Bakke 9 (RB).

\section{*Pilosocereus brasiliensis (Britton \& Rose) Backeb.}

Hábito

Hábitat

Distribuição geográfica

Estado de conservação (RJ)

Comentários

Ocorrência em UC

Estado de conservação global
Rupícola

Floresta atlântica, restinga

Brasil: BA, MG, ES e RJ (blocos: Norte Fluminense, Região dos Lagos e Metropolitano).

VU

Hábitat natural sofrendo grande pressão antrópica. Conhecida em apenas três localidades e provavelmente pouco freqüente.

Dentro de UC

$\mathrm{DD}$

Material examinado: (G33) R.Marquete 556 (RB), L.Scheinvar 6230 (RB).

**Pilosocereus ulei (K. Schum.) Byles \& Rowley

Hábito

Hábitat

Distribuição geográfica

Estado de conservação (RJ)

Comentários

Ocorrência em UC

Estado de conservação global

Material examinado: (F25) s/coletor (GUA 32603), Barroso 12 (RB).

*Rhipsalis campos-portoana Loefgr.

Hábito

Hábitat

Distribuição geográfica

Estado de conservação (RJ)

Comentários

Ocorrência em UC

Terrícola, rupícola

Restinga

Brasil: RJ (bloco Região dos Lagos).

EN

Endêmico da região de Cabo Frio. Está sujeita à grande pressão antrópica. Dependente da adequada conservação das áreas em que ocorre.

Fora de UC

$\mathrm{VU}$
Epífita

Floresta atlântica

Brasil: MG, ES, RJ (blocos: Serrano Central e Metropolitano), SP, PR e SC. LC

Dentro e fora de UC

Estado de conservação global LR

Material examinado: (B8) Vieira 56 (FCAB), Siqueira 2383 (FCAB); (C11) Markgraf 10187 (RB); (C12) Ribeiro 926 (GUA); (G28) Lima 2290 (RB); (G33) Sucre 10029 (RB), Jaques 80 (RB), Ribeiro 2293 (GUA).

\section{*Rhipsalis cereoides (Backeb. \& Voll) Backeb.}

Hábito

Hábitat

Distribuição geográfica

Estado de conservação (RJ)

Comentários

Ocorrência em UC

Estado de conservação global

Floresta atlântica

Brasil: ES e RJ (bloco Metropolitano).

VU

Conhecida apenas em duas localidades em áreas com grande ação antrópica. Dependente de ad equada conservação do seu hábitat natural.

Dentro de UC VU

Material examinado: (G32) Farney 92 (RB), Pereira da Silva 342 (GUA), Scheinvar 6295 (RB), Andreata $326,545,886$ (RUSU), Plowman 13935 \& Andreata 650 (RB), Trece 52 (R), Ferreira 3959 (GUA); (G33) Scheinvar 6226 (RB). 


\section{Rhipsalis cereuscula Haw.}

$\begin{array}{ll}\text { Hábito } & \text { Epífita, rupícola } \\ \text { Hábitat } & \text { Floresta atlântica } \\ \text { Distribuição geográfica } & \text { Brasil: PE, BA, MG, MS, RJ (bloco Serra da Mantiqueira), SP, PR, SC, RS; } \\ & \text { Bolívia, Paraguai, Uruguai e Argentina. } \\ \text { Estado de conservação (RJ) } & \text { NT } \\ \text { Comentários } & \text { Provavelmente rara no estado. Dependente de adequada conservação do seu } \\ & \text { hábitat natural. } \\ \text { Ocorrência em UC } & \text { Dentro de UC } \\ \text { Estado de conservação global } & \text { LR } \\ \text { rial examinado: (E19) Campos Porto } 838(\mathrm{RB}), \text { Otto Voll s/n (RB 48553). }\end{array}$

Material examinado: (E19) Campos Porto 838 (RB), Otto Voll s/n (RB 48553).

\section{*Rhipsalis clavata F.A.C. Weber}

Hábito
Hábitat
Distribuição geográfica
Estado de conservação (RJ)
Comentários

$\begin{array}{ll}\text { Ocorrência em UC } & \text { Dentro e fora de UC } \\ \text { Estado de conservação global } & \text { LR }\end{array}$

Material examinado: (B6) Araujo 950 (GUA), Marquete 2055 (RB); (C11) Brade 16658 (RB), Sampaio 1843 (R); (C12) Cesar Diogo 681 (R), Duarte 1497 (RB); (G28) Martinelli 9946 (RB), Martinelli 9914 (GUA); (G33) Castellanos 23360 (GUA), Araujo 882 (GUA), Sucre 9500, 9522 (RB), Constantino s/n (RB 7813), Martinelli 3594 (GUA), Glaziou 10888 (R), Strang 641 (GUA), Scheinvar 6255 (RB); (H36) Freitas 144 (RB).

\section{*Rhipsalis crispata (Haw.) Pfeiff.}

Hábito

Hábitat

Distribuição geográfica

Estado de conservação (RJ)

Comentários

Ocorrência em UC

Estado de conservação global
Epífita

Floresta atlântica

Brasil: MG, ES, RJ (blocos: Serrano Central, Metropolitano e Sul Fluminense) e SP. LC

Material examinado: (B9) Carauta 2526 (GUA); (F24) Sucre 3955 (RB); (F25) Freitas 225 (R); (F26) Freitas 56 (RB).

\section{*Rhipsalis elliptica G.A. Lindberg ex K. Schum.}

Hábito

Hábitat

Distribuição geográfica

Estado de conservação (RJ)

Comentários

Ocorrência em UC

Estado de conservação global
Epífita

Floresta atlântica, restinga

Bras il: PE, RJ (blocos: Serrano Central e Região dos Lagos) e SP.

DD

Pouco coletada/ Rara?

Dentro e fora de UC

VU

Material examinado: (B7) Neves Armond 337 (R); (B8) Capell s/n (FCAB 0710); (C11) Hunt 6485, 6511 (RB), Martinelli 3318 (RB); (G33) Brade 10955 (R), Vilaça 92 (GUA), Farney 2396 (RB), Sucre 7052 (GUA), Rocha 204 (GUA), Costa 211 (GUA), Pereira 4076 (RB), Glaziou 14859 (R), Braga 3554 (RUSU), Vidal s/n (R 91080), Menezes 781 (RBR), Occhioni 2193 (RFA); (H35) Araujo 3997, 5710 (GUA), Pedrosa 1049 (GUA), Carauta 2906 (GUA), Gomes 29 (HB).

\section{**Rhipsalis ewaldiana Barthlott \& N.P. Taylor}

Hábito

Hábitat

Distribuição geográfica

Estado de conservação (RJ)

Comentários

Ocorrência em UC

Estado de conservação global

\section{Epífita}

Floresta atlântica, restinga SP, PR e SC.

LC

Dentro e fora de UC

Epífita

Floresta atlântica

Brasil: RJ (provável da Serra dos Órgãos).

DD

Não foram encontrados exemplares. Des crita de material cultivado obtido em Nova Friburgo.

Sem dados

DD 


\section{Rhipsalis floccosa Salm-Dyck ex Pfeiff.}

$\begin{array}{ll}\text { Hábito } & \text { Epífita } \\ \text { Hábitat } & \text { Floresta atlântica } \\ \text { Distribuição geográfica } & \text { Venezuela, Brasil: PE, } \\ & \text { Central, Serra da Mant } \\ & \text { RS. } \\ \text { Estado de conservação (RJ) } & \text { LC } \\ \text { Comentários } & \\ \text { Ocorrência em UC } & \text { Dentro e fora de UC } \\ \text { Estado de conservação global } & \text { LR }\end{array}$

Material examinado: (A5) Strang 1371 (RB); (B6) Leitman 213 (RB); (B8) Pabst 1959 (GUA), Capell s/n (FCAB 711); (C12) Sucre 10661 (RB), Neves Armond s/n (R 30776); (E19) Freitas 62, 64 (RB); (G29) Emmerich 857 (R); (G31) Araujo 5376 (GUA); (G33) Castellanos 22443 (R), Pereira 3980, 5732 (RB), Braga 3644 (RUSU), Mallemont 78 (R); (H36) Almeida 17 (RB), Freitas $94(\mathrm{RB})$.

\section{* Rhipsalis grandiflora Haw.}

\section{Hábito}

Hábitat

Distribuição geográfica

Estado de conservação (RJ)

Comentários

Ocorrência em UC

Estado de conservação global

\section{Epífita}

Floresta atlântica, restinga

Brasil: RJ (blocos: Metropolitano e Sul Fluminense), SP, PR e SC.

NT

Hábitat reduzido devido à urbanização.

Dentro e fora de UC

LR

Material examinado: (G28) Lima 2182 (RB); (G32) Andreata 303 (RB); (G33) Brade 18586 (RB), Brade11194 (R), Castelanos 23358, 25702 (GUA), Angeli 381 (GUA), Rizzini 353 \& Barros 45 (RFA), Vianna s/n (RB), Martins 359 (GUA), Lanna Sobrinho 1195 (GUA), Carauta 3261, 3353, 3416, 6882 (GUA), Scheinvar 6239, 6276 (RB), Maciel s/n (GUA 37806); (H35) Araujo 6064 (GUA).

\section{*Rhipsalis lindbergiana K. Schum.}

Hábito

Hábitat

Distribuição geográfica

Estado de conservação (RJ)

Comentários

Ocorrência em UC

\section{Epífita}

Floresta atlântic a, restinga

Brasil: PE, SE, BA, MG, ES, RJ (blocos: Norte Fluminense, Serrano Central, Central Sul, Região dos Lagos, Metropolitano, e Sul Fluminense) e SP. $\mathrm{LC}$

Dentro e fora de UC

$\mathrm{nt}$

Material examinado: (A2) Araujo 8893 (GUA); (A3) Sampaio 8455 (R); (A5) Araujo 3692 (GUA); (B8) Vianna 1762 (GUA); (C10) Scheinvar 5535 (RB); (C12) Smith 6479, 6480 (R), Scheinvar 6343 (RB); (D14) Martins 523 (GUA); (D15) Scheinvar 6319 (RB); (D16) Vianna 1740 (GUA), Carauta 5047, 5088 (GUA); (F26) Araujo 8376 (GUA), Freitas 215 (R); (G30) Carauta 6153 (GUA); (G31) Rizzini 433 (RFA), Scheinvar 5579 (RB); (G33) Brade s/n (R 30771, 91046), Brade 10418 (R), Brade 15006 (RB), Castellanos 23448 (GUA), Ule s/n (R 30774), Martins 278 (GUA), Braga 238 (RUSU), Carauta 1654, 6764, 6785, 7055 (GUA), Paixão 180 (RBR), Giordano 324 (RB), Scheinvar 5574, 6235a, 6251, 6265, 6269, 6275a, 6329, 6304, 6335, 6338 (RB), Freitas 61 \& Scheinvar 5578 (RB), Freitas 77 (RB), Vianna 1548 (GUA); (H35) Araujo 9851 (GUA).

**Rhipsalis mesembryanthemoides Haw.

Hábito

Hábitat

Distribuição geográfica

Estado de conservação (RJ)

Comentários

Ocorrência em UC

Estado de conservação global VU

Campos Porto s/n (RB 8829), Glaziou 18265 (R), Kuhlman s/n (RB 83880), Scheinvar 6227 (RB), Lad. Neto s/n (R 91015).

\section{Epífita}

Floresta atlântica

Brasil: RJ (bloco Metropolitano).

EN/ Ameaçada

Endêmica da área urbana do município do Rio de Janeiro. Hábitat reduzido e descaracterizado devido à urbanização intensa.

Dentro e fora de UC

$\mathrm{VU}$ 
*Rhipsalis neves-armondii K.Schum.

$\begin{array}{ll}\text { Hábito } & \text { Epífita, rupícola } \\ \text { Hábitat } & \text { Floresta atlântica } \\ \text { Distribuição geográfica } & \text { Brasil: RJ (blocos: Serrano Central, Metropolitano e Sul Fluminense), SP, PR } \\ & \text { e SC. } \\ \text { Estado de conservação (RJ) } & \text { NT } \\ \text { Comentários } & \text { Hábitat reduzido devido à urbanização. } \\ \text { Ocorrência em UC } & \text { Dentro e fora de UC } \\ \text { Estado de conservação global } & \text { LR } \\ \text { rial examinado: (C11) Brade 16294 (RB); (G29) Castellanos 23153 (GUA); (G32) Andreata 303, } 592 \text { (RUSU); (G33) }\end{array}$
Castellanos 23561 (GUA), Braga 3557 (RUSU), Carauta 602 (GUA); (H35) Castellanos 23908 (GUA).

\section{*Rhipsalis oblonga Loefgr.}

Hábito
Hábitat
Distribuição geográfica
Estado de conservação (RJ)
Comentários
Ocorrência em UC
Estado de conservação global

\section{Epífita}

Floresta atlântica, restinga

Brasil: BA, ES, RJ (blocos: Serrano Central, Região dos Lagos, Metropolitano e SulFluminense) e SP.

LC

Hábitat reduzido devido à urbanização.

Dentro e fora de UC

Material examinado: (B6) Marquete 2017 (RB); (C11) Hunt 6512 (RB), Martinelli 1778 (RB), Scheinvar 5571 (RB); (F26) Freitas 299 (GUA), s/coletor (R); (G33) Brade 11981 (R), Castellanos 23362 (GUA), Angeli 304 (GUA), Araujo 9548 (GUA), Ule 3790, 4490 (R), Braga 3360 (RUSU), Mello Filho 1320 (R), Scheinvar 6236, 6264 (RB), Lad. Neto s/n (R 91028), Marquete 2007 (RB); (G34) Maciel s/n (GUA37795); (H35) Castellanos 23897 (GUA), Vilaça 104 (GUA), Araujo 6694, 7282 (GUA); (H36) Freitas 97, 119, 142, 143, 158, 160 (RB).

\section{* Rhipsalis olivifera N.P. Taylor \& Zappi}

Hábito

Hábitat

Distribuição geográfica

Estado de conservação (RJ)

Comentários

Ocorrência em UC

Estado de conservação global
Epífita

Floresta atlântica

Brasil: RJ (bloco Serrano Central) e SP.

DD

Espécie descrita recentemente. Foi encontrado apenas um exemplar (Holótipo).

Material examinado: (C11) Martinelli 9038 (RB).

**Rhipsalis ormindoi N.P. Taylor \& Zappi

Hábito Epífita?

Hábitat

Floresta atlântica

Distribuição geográfica

Estado de conservação (RJ)

Comentários

Brasil: RJ (bloco Serrano Central).

DD

Espécie descrita recentemente. Foi encontrado apenas um exemplar (Holótipo). Endêmica de Nova Friburgo (Macaé de Cima).

Ocorrência em UC Dentro de UC

Estado de conservação global

Material examinado: (B8) Correa 164 (RB).

\section{*Rhipsalis pacheco-leonis Loefgr.}

Hábito

Hábitat

Distribuição geográfica

Estado de conservação (RJ)

Comentários

Ocorrência em UC

Estado de conservação global
Epífita

Floresta atlântica

Brasil: ES e RJ.

DD

Não foram encontrados exemplares.

Sem dados

DD 
*Rhipsalis pachyptera Pfeiff.

Hábito
Hábitat
Distribuição geográfica
Estado de conservação (RJ)
Comentários
Ocorrência em UC
Estado de conservação global

\section{Epífita}

Floresta atlântica, restinga

Brasil: RJ (blocos: Serrano Central, Serra da Mantiqueira, Região dos Lagos, Metropolitano e Sul Fluminense), SP, PR, SC e RS.

LC

Dentro e fora de UC

LR

Material examinado: (B8) Sucre 6498 (RB); (C11) Castellanos 23172 (GUA), Castellanos s/n (GUA 7981); (C12) Marquete 159 (RB), Ribeiro 698 (GUA), Klein 701 (RB); (E18) Ule 3788 (R); (F26) Freitas 212 (R); (G27) Buwahi 951 (R); (G32) Andreata 302 (RUSU); (G33) Duarte 4807 (RB), Sucre 5075, 10026 (RB), Strang 166 (GUA), Scheinvar 5575 (RB), Marquete 584, 1038 (RB), s/coletor (R 9811), Schwacke s/n (R 91027); (G34) Castellanos 24016 (GUA), Braga 3483 (RUSU); (H35) Araujo 6214, 9843, 9862 (GUA), Martinelli 63, 481, 482 (RB); (H36) Martinelli 554 (RB), Freitas 80, 83, 86, 96, 101, 117, 118, 128, 137, 138, 153, 155, 157 (RB).

\section{*Rhipsalis paradoxa (Salm-Dyck ex Pfeiff.) Salm-Dyck}

Hábito

Hábitat

Distribuição geográfica

Estado de conservação (RJ)

Comentários

Ocorrência em UC

Estado de conservação global

\section{Epífita}

Floresta atlântica,

Brasil: PE, BA, MG, ES, RJ (blocos: Serrano Central, Metropolitano e Sul Fluminense), SP, PR e SC.

NT

Hábitat reduzido devido ao desmatamento.

Dentro e fora de UC

LR

Material examinado: (B7) Neves Armond 343 (R); (G34) Bovini 1090 (RUSU), Lira Neto 522 (RUSU), Braga 3443 (RUSU); (H36) Martinelli 13465 (RB), Freitas 110, 147 (RB).

\section{**Rhipsalis pentaptera Pfeiff. ex A.Dietr.}

Hábito

Hábitat

Distribuição geográfica

Estado de conservação (RJ)

Comentários

Ocorrência em UC

Estado de conservação global
Epífita

Floresta atlântica,

Brasil: RJ (bloco Metropolitano)

CR

Só é conhecida em uma localidade na área urbana do município do Rio de Janeiro.

Fora de UC

EW

\section{Epífita}

Floresta atlântica

Brasil: MG, ES, RJ (blocos: Serrano Central e Serra da Mantiqueira), SP e PR.

VU

Conhecida em apenas duas localidades no estado. Hábitat reduzido/alterado devido à ação antrópica. Táxon raro ocorrente em matas bem preservadas. Dentro de UC

Ocorrência em UC

Estado de conservação global VU

Material examinado: (E19) Castellanos 23328 (GUA), Campos Porto 103 (RB). 


\section{*Rhipsalis pulchra Loefgr.}

$\begin{array}{ll}\text { Hábito } & \text { Epífita } \\ \text { Hábitat } & \text { Floresta atlântica } \\ \text { Distribuição geográfica } & \text { Brasil: MG, RJ (blocos: Serrano Central, Serra da Mantiqueira e Metropolitano) } \\ & \text { e SP. } \\ \text { Estado de conservação (RJ) } & \text { NT } \\ \text { Comentários } & \text { Hábitat reduzido devido à ação antrópica. } \\ \text { Ocorrência em UC } & \text { Dentro e fora de UC } \\ \text { Estado de conservação global } & \text { DD }\end{array}$

Material examinado: (C11) Brade 9049, 9329, 9383 (R), Castellanos 23079 (GUA), Vilaça 151 (GUA), Mello Filho 848 (R); (C11/C12) Brade 16661, 20051 (RB), Hunt 6486 (RB); (E18) Martinelli 3221 (GUA); (E19) Freitas 73 (RB); (G33) Glaziou $18263(\mathrm{R})$.

\section{*Rhipsalis puniceodiscus G.A. Lindb.}

Hábito

Hábitat

Distribuição geográfica

Estado de conservação (RJ)

Comentários

Ocorrência em UC

Estado de conservaça

Epífita

Floresta atlântica

Brasil: RJ (bloco Metropolitano), SP, PR e SC.

$$
\text { DD }
$$

Pouco coletada, distribuição restrita, ameaçada ou rara?

Dentro de UC

Material examinado: (G33) Castellanos 23354a, 23359 (GUA), Brade 10417 (R), Pereira 3980 (RB), Lanna Sobrinho 1157 (GUA).

\section{*Rhipsalis teres (Vell.)Steud.}

Hábito

Hábitat

Distribuição geográfica

Estado de conservação (RJ)

Comentários

Ocorrência em UC

Estado de conservação global

\section{Rupícola, epífita}

Floresta atlântica, restinga

Brasil: MG, RJ (blocos: Norte Fluminense, Serrano Central, Região dos Lagos, Metropolitano e Sul Fluminense), SP, PR, SC e RS.

LC

Dentro e fora de UC

LR

Material examinado: (A5) Glaziou 18264 (R); (B8) Martinelli 11705, 11782 (RB); (C11) Brade 9671 (R), Vaz 472 (RB), Vieira 229 (RB); (C11/C12) Brade 20052 (RB); (F24) Souza 2499 (R), Sucre 9540 (RB); (G28) Lima 2290 (GUA); (G29) Castellanos 23165 (R); (G31) Araujo 7400 (GUA), Freitas 41 (RB), Occhioni 8307, Rizzini 3 (RFA); (G32) Peixoto 5 (GUA); (G33) Rizzini s/n (RB 282349), Sucre 10052 (GUA), Ule 3789 (R), Glaziou 18261 (R), Braga 3643 (RUSU), Lanna 607, 671 (GUA), Scheinvar 6238, 6256, 6275 (RB), Freitas 75, 76 (RB), Marquete 1009, 1036, 1852 (RB), s/coletor (R 91045), Siqueira s/n (R 91089); (G34) Lira Neto 433 (RUSU), Braga 3416 (RUSU); (H35) Sucre 10673 (RB); (H36) Freitas 92, 93, 111, 112, 148, 159 (RB).

\section{*Schlumbergera microsphaerica (K.Schum.) Hövel}

Hábito

Hábitat

Distribuição geográfica

Estado de conservação (RJ)

Comentários

Ocorrência em UC

Estado de conservação global
Rupícola, epífita

Floresta atlântica

Brasil: MG, ES e RJ (bloco Serra da Mantiqueira).

DD

Não foram observados exemplares. Ocorre em Itatiaia segundo a bibliografia.

Sem dados

DD 


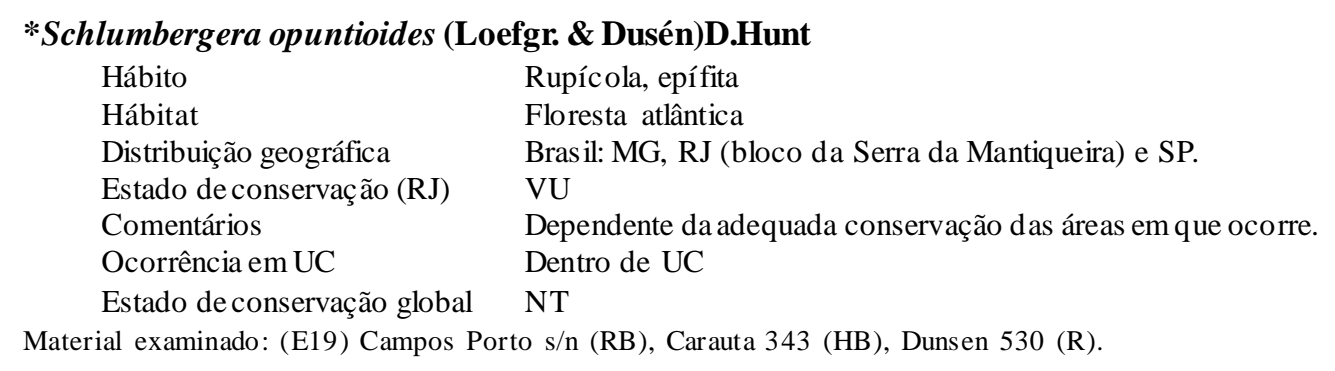

*Schlumbergera orssichiana Barthlott \& McMillan

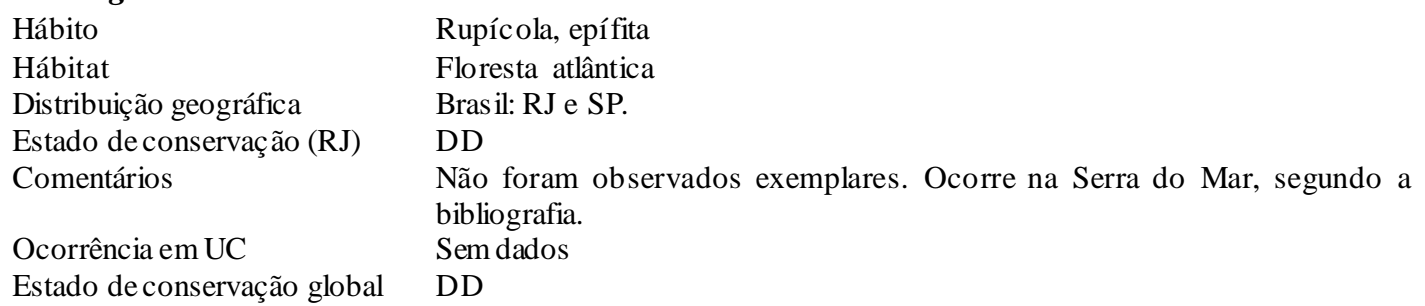

**Schlumbergera russelliana (Hook.) B ritton \& Rose

Hábito Rupícola, epífita

Hábitat Floresta atlântica

Distribuição geográfica Brasil: RJ (bloco Serrano Central).

Estado de conservação (RJ)

Comentários

VU

Hábitat reduzido devido à ação antrópica. Dependente da adequada conservação das áreas em que ocorre.

Ocorrência em UC Dentro e fora de UC

Estado de conservação global CD?

Material examinado: (B8) Jacques 141 (RB); (C11) Brade 16715, 20397 (RB), Brade 10416, 11537 (R), Santos 200, From 178, Flastes 169 \& Trinta 109 (RB), Strang s/n (HB 47947), Barcia 97 (R); (C12) Campos Goes s/n (RB 49524).

**Schlumbergera truncata (Haw.) Moran

$\begin{array}{ll}\text { Hábito } & \text { Rupícola, epífita } \\ \text { Hábitat } & \text { Floresta atlântica } \\ \text { Distribuição geográfica } & \text { Brasil: RJ (blocos: Serrano Central e Metropolitano). } \\ \text { Estado de conservação (RJ) } & \text { NT/Ameaçada } \\ \text { Comentários } & \text { Hábitat reduzido devido à ação antrópica. } \\ \text { Ocorrência em UC } & \text { Dentro e fora de UC } \\ \text { Estado de conservação global } & \text { CD? }\end{array}$

Material examinado: (B8) Giordano 1898 (RB); (C11) Sucre 3181 (RB), Pabst 9136 (HB), Martinelli 1661 (RB), Maas 3266 (RB); (C12) Passarelli 142 (R), Farney 770 (RB), Sucre 2451 (RB), Campos Goes 601, 605, 624 (RB); (G33) Brade 17381 (RB), Sucre 5083 \& Plowman 2780 (RB), Ule s/n (R 91107), Ule 3792 (R), Martinelli 1225 (RB), Scheinvar 6332 (RB).

\section{Conclusão}

Deve-se alertar que são poucas as coletas realizadas fora de unidades de conservação ou dos municípios nos quais essas estão localizadas. Tal fato demonstra a necessidade de se ampliar esforços de coleta além das unidades de conservação. Isso permitirá identificar áreas carentes de conservação, embora ricas em espécies. A gravidade deste fato pode ser explicitada pela ausência de exemplares coletados em 56 municípios, representando $60 \%$ do total, muitos dos quais localizados nas bacias do rio Paraíba, a oeste do estado (Região D e parte de B) e do rio Itabapoana, ao norte (Fig. 1).

Esforços de pesquisa e de conservação devem se concentrar no bloco da Serra da Mantiqueira, pois ele abriga táxons endêmicos, de distribuição restrita e/ou pouco conhecidos. Já no bloco Metropolitano, evidenciado como 
um enclave dos limites norte-sul da distribuição de várias espécies e que apresenta alta riqueza e endemismo, faz-se necessário que se priorizem medidas de conservação. O mesmo é almejado para a Região dos Lagos, carente de unidades de conservação que garantam a sobrevivência das espécies endêmicas e ameaçadas.

Alguns exemplares do gênero Rhipsalis encontrados nas coleções dos herbários não foram incluídos neste levantamento devido a dúvidas quanto a sua correta identificação. Nota-se uma grande dificuldade na determinação dos táxons desse gênero por várias razões, como o pouco conhecimento da sua taxonomia, pela sobreposição dos caracteres diagnósticos às vezes não claramente delimitados, pela dificuldade decorrente da perda de elementos fundamentais durante o processo de herborização ou, por não serem coletadas corretamente (as plantas do gênero devem ser coletadas férteis, compreendendo toda a extensão dos ramos e suas variações da base ao ápice). As características, como cores das flores e frutos, devem ser detalhadamente registradas. Como exemplo, Rhipsalis lindbergiana e $R$. baccifera, constantemente confundidas, ou ainda, $R$. oblonga $\operatorname{com} R$. elliptica, $R$. crispata e $R$. pachyptera. Estas observações demonstram a necessidade de mais estudos como o aprofundamento da taxonomia, morfologia interna e ecologia do grupo e de uma revisão do gênero em questão.

Sendo assim, o futuro tratamento das Cactáceas para a flora do estado do Rio de Janeiro demandará estudos adicionais taxonômicos e de campo.

\section{Agradecimentos}

As autoras agradecem as valiosas e enriquecedoras sugestões de dois revisores anônimos.

\section{REFERÊNCIAS BIBLIOG RÁFICAS}

Barthlott, W. \& Taylor, N. P. 1995. Notes towards a Monograph of Rhipsalideae (Cactaceae). Bradleya 13: 43-79.
Castellanos, A. 1961. Flórula da Guanabara (Cactaceae). Vellozia 1 (1): 5-13. 1962. Contribuição ao conhecimento da Flórula da Guanabara. Cactaceae II. Vellozia 1 (2): 74-80.

1963. Contribuição ao conhecimento da Flórula da Guanabara. Cactaceae III. Vellozia 1 (3): 103-106.

1964. Contribuição ao conhecimento da Flórula da Guanabara. Cactaceae IV. Vellozia 1 (4): 139-144.

Costa, L. H. P. 2000. Cactaceae. In: Secretaria Municipal do Meio Ambiente. Espécies ameaçadas de extinção no município do Rio de Janeiro: Flora e Fauna. Secretaria Municipal do Meio Ambiente, Rio de Janeiro, p. 22.

Forzza, R. C.; Christianini, A. V.; Wanderley, M. G. L. \& Buzato, S. 2003. Encholirium (Pitcarinioideae - Bromeliaceae): Conhecimento atual e sugestões para conservação. Vidalia 1 (1): 7-20.

Freitas, M. F. 1990/1992. Cactaceae da Área de Proteção Ambiental da Massambaba, Rio de Janeiro Brasil. Rodriguésia 42/44: 67-91.

1996. Cactaceae. In: Lima, M. P. M. \& Guedes-Bruni, R. R. (org.). Reserva Ecológica de Macaé de Cima, Nova Friburgo, RJ. Aspectos florísticos das espécies vasculares v.2. Rio de Janeiro. Jardim Botânico do Rio de Janeiro, 153-161. 1997. Cactaceae Juss. In: Marques, M. C. M. \& Vaz, A. S. F.; Marquete, R. (org.). Flora da APA Cairuçu, Parati, RJ. Espécies Vasculares. Jardim Botânico do Rio de Janeiro, Rio de Janeiro, p. 105117.

Holmgren, P. K.; Holmgren, N. H. \& Barnett, L. C. 1990. Index herbariorum Part I: The herbaria of the world. 8 ed. New York Botanical Garden, New York, 693 p.

Hunt, D. (Comp.) 1999. Cites Cactaceae Checklist. 2 ed. Kent. Whitstable Litho Ltd, Whitstable, $315 \mathrm{p}$.

IUCN. (2001). IUCN Red List Categories and Criteria: Version 3.1. IUCN Species 
Survival Commission, Gland, Switzerland and Cambridge, UK, $30 \mathrm{p}$.

(2003). Directrices para emplear los criterios de la Lista Roja de la UICN a nivel regional: Versión 3.0. Comisión de Supervivencia de Especies de la UICN, Gland, Suiza y Cambridge, Reino Unido, 26p.

Löfgren, A. 1915. O gênero Rhipsalis. Arquivos do Jardim Botânico do Rio de Janeiro 1: 59-104.

1918. Novas Contribuições para o Gênero Rhipsalis. Arquivos do Jardim Botânico do Rio de Janeiro 2: 34-45.

Mc Millan, A. J. S. \& Horobin, J. F. 1995. Christmas Cacti-The genus Schlumbergera and its hybrids. Succulent Plant Research 4.

Meirelles, S. T.; Pivello, V. R. \& Joly, C. A. 1999. The vegetation of granite rock outcrops in Rio de Janeiro, Brazil, and the need for its protection. Enviromental Conservation 26(1): 10-20.

Mendonça, M. P. \& Lins, L. V. (org.). 2000. Lista vermelha das espécies ameaçadas de extinção da flora de Minas Gerais. Fundação Biodiversitas, Fundação ZôoBotânica de Belo Horizonte, Belo Horizonte, $157 \mathrm{p}$.

Mittermeier, R. A.; Myers, N.; Gil, P. R. \& Mittermeier, C. G. 2000. Hotspots: Earth's biologically richest and most endangered terrestrial ecoregions. CEMEX/Conservation International, Mexico City, $430 \mathrm{p}$.

Primack, R. B. \& Rodrigues, E. 2001. Biologia da Conservação. E. Rodrigues, Londrina, $328 \mathrm{p}$.

Rocha, C. F. D.; Bergallo, H. G.; Alves, M. A. S. \& Sluys, M. V. A. 2003. Biodiversidade dos grandes remanescentes florestais do estado do Rio de Janeiro e nas restingas da Mata Atlântica. Ed. Rima, São Carlos, SP, 160 p.

Scheinvar, L.; Cardoso, A. A.; Silva, D. C. P. \& Eleutério, J. C. 1996. Cactáceas da Reserva Florestal da Vista Chinesa. Albertoa 4 (11): 117-136.

Schumann, K. M. 1890. Cactaceae. In: Martius, C. F. P. von; Eichler, A. W. \& Urban, I. Flora Brasiliensis. München, Wien, Leipzig, 4(2): 266-300.

Taylor, N. P. 1997 Cactaceae. In: Oldfield, S. (comp.). Cactus and succulent plants Status Survey and Conservation Action Plan. Cactus and Succulent Specialist Group IUCN/SSC, Gland, Switzerland and Cambridge, UK, p. 17-20, 199-202. 2000. Taxonomy and Phytogeography of the Cactaceae of Eastern Brazil. PhD Thesis - The Open University. 2001. Melocactus Violaceus, Pilosocereus arrabidae, Rhipsalis cereoides, Rhipsalis crispata, Rhipsalis oblonga, Rhipsalis pacheco-leonis, Rhipsalis pilocarpa, Schlumbergera microsphaerica, Schlumbergera opuntioides. In: IUCN 2003. 2003 IUCN Red List of Threatened Species $\langle$ www.redlist.org $\rangle$. consultado em 22 de Junho de 2004.

Taylor, N. P. \& Zappi, D. C. 1997. Cactaceae Consensus Initiatives 3: 8.

2004. Cacti of Eastern Brazil. Richmond, Surrey, UK. The Royal Botanic Gardens, Kew, 499 p.

Zappi, D. C. 1994. Pilosocereus (Cactaceae). The genus in Brazil. Succulent Plant Research 3. 
